\title{
Yield of peripheral sodium channels gene screening in pure small fibre neuropathy
}

Citation for published version (APA):

Eijkenboom, I., Sopacua, M., Hoeijmakers, J., de Greef, B., Lindsey, P., Almomani, R., Marchi, M., Vanoevelen, J., J.M. Smeets, H., Waxman, S. G., Lauria, G., Merkies, I., Faber, K., \& Gerrits, M. (2019). Yield of peripheral sodium channels gene screening in pure small fibre neuropathy. Journal of Neurology Neurosurgery and Psychiatry, 90(3), 342-352. https://doi.org/10.1136/jnnp-2018-319042

Document status and date:

Published: 01/03/2019

DOI:

10.1136/jnnp-2018-319042

Document Version:

Publisher's PDF, also known as Version of record

Document license:

Taverne

Please check the document version of this publication:

- A submitted manuscript is the version of the article upon submission and before peer-review. There can be important differences between the submitted version and the official published version of record.

People interested in the research are advised to contact the author for the final version of the publication, or visit the DOI to the publisher's website.

- The final author version and the galley proof are versions of the publication after peer review.

- The final published version features the final layout of the paper including the volume, issue and page numbers.

Link to publication

\footnotetext{
General rights rights.

- You may freely distribute the URL identifying the publication in the public portal. please follow below link for the End User Agreement:

www.umlib.nl/taverne-license

Take down policy

If you believe that this document breaches copyright please contact us at:

repository@maastrichtuniversity.nl

providing details and we will investigate your claim.
}

Copyright and moral rights for the publications made accessible in the public portal are retained by the authors and/or other copyright owners and it is a condition of accessing publications that users recognise and abide by the legal requirements associated with these

- Users may download and print one copy of any publication from the public portal for the purpose of private study or research.

- You may not further distribute the material or use it for any profit-making activity or commercial gain

If the publication is distributed under the terms of Article $25 \mathrm{fa}$ of the Dutch Copyright Act, indicated by the "Taverne" license above, 


\title{
Yield of peripheral sodium channels gene screening in pure small fibre neuropathy
}

\author{
Ivo Eijkenboom, ${ }^{1,2}$ Maurice Sopacua, ${ }^{2,3}$ Janneke G J Hoeijmakers, ${ }^{2,3}$ \\ Bianca T A de Greef, ${ }^{2,3}$ Patrick Lindsey, ${ }_{1}^{1}$ Rowida Almomani, ${ }^{1,2,4}$ Margherita Marchi, ${ }^{5}$ \\ Jo Vanoevelen, ${ }^{1}$ Hubertus J M Smeets, ${ }^{1,2}$ Stephen G Waxman, ${ }^{6,7}$ Giuseppe Lauria, ${ }^{5,8}$ \\ Ingemar S J Merkies, ${ }^{2,9}$ Catharina G Faber, ${ }^{2,3}$ Monique M Gerrits ${ }^{10}$
}

\begin{abstract}
- Additional material is published online only. To view please visit the journal online (http://dx.doi.org/10.1136/ jnnp-2018-319042).
\end{abstract}

For numbered affiliations see end of article.

\section{Correspondence to} Dr Monique M Gerrits, Department of Clinical Genetics, Maastricht University Medical Centre+, P.O. Box 5800, 6202AZ Maastricht, The Netherlands; monique.gerrits@ mumc.nl

IE and MS contributed equally.

Received 18 June 2018 Revised 1 November 2018 Accepted 18 November 2018 Published Online First 15 December 2018

\begin{abstract}
Background Neuropathic pain is common in peripheral neuropathy. Recent genetic studies have linked pathogenic voltage-gated sodium channel (VGSC) variants to human pain disorders. Our aims are to determine the frequency of SCN9A, SCN10A and SCN11A variants in patients with pure small fibre neuropathy (SFN), analyse their clinical features and provide a rationale for genetic screening.

Methods Between September 2009 and January 2017, 1139 patients diagnosed with pure SFN at our reference centre were screened for SCN9A, SCN10A and SCN11A variants. Pathogenicity of variants was classified according to established guidelines of the Association for Clinical Genetic Science and frequencies were determined. Patients with SFN were grouped according to the VGSC variants detected, and clinical features were compared.
\end{abstract}

Results Among 1139 patients with SFN, 132 (11.6\%) patients harboured 73 different (potentially) pathogenic VGSC variants, of which 50 were novel and 22 were found in $\geq 1$ patient. The frequency of (potentially) pathogenic variants was $5.1 \%(n=58 / 1139)$ for SCN9A, $3.7 \%(n=42 / 1139)$ for SCN1OA and $2.9 \%(n=33 / 1139)$ for SCN11A. Only erythromelalgia-like symptoms and warmth-induced pain were significantly more common in patients harbouring VGSC variants.

Conclusion (Potentially) pathogenic VGSC variants are present in $11.6 \%$ of patients with pure SFN. Therefore, genetic screening of SCN9A, SCN10A and SCN11A should be considered in patients with pure SFN, independently of clinical features or underlying conditions.

\section{INTRODUCTION}

According to the International Association for the Study of Pain (IASP), pain is defined as an unpleasant sensory and emotional experience associated with actual or potential tissue damage. As in neuropathic pain the somatosensory nervous system is affected, ${ }^{1}$ it is not surprising that pain is frequently reported in peripheral neuropathy, especially when the small diameter sensory nerve fibres are involved. ${ }^{2}$ Pure small fibre neuropathy (SFN) is a peripheral neuropathy in which the thinly myelinated $A \delta$-fibres and unmyelinated C-fibres are selectively affected, leading to sensory symptoms and autonomic dysfunction. ${ }^{2}$ In general, neuropathic pain is the main symptom, reflected by allodynia and hyperalgesia, but also thermal sensory loss, pinprick loss, restless legs syndrome, sicca syndrome, accommodation problems, hyperhidrosis or hypohydrosis, micturation disturbances, impotence and/or diminished ejaculation or lubrication, bowel disturbances (constipation, diarrhoea, irritability, gastroparesis, cramps), hot flushes, orthostatic dizziness and cardiac palpitations may be present. ${ }^{2}$ Pharmacotherapy for neuropathic pain in SFN is challenging since the efficacy of currently available medications is moderate and side-effects are often dose-limiting. ${ }^{34}$ A better understanding of genetic causes and pathophysiology of peripheral neuropathy may provide a basis for development of more effective, personalised treatment.

Voltage-gated sodium channels (VGSCs) are integral membrane polypeptides that are mainly present in excitable cells. The large $\alpha$-subunit is constructed of four homologous domains (DI-DIV) with six transmembrane segments (S1-S6), forming an ion-selective pore. Associated smaller auxiliary $\beta$-subunits contribute to targeting and anchoring of the channel at specific sites in the plasma membrane, modulating gating properties of the $\alpha$-subunit. ${ }^{5}$ VGSCs $\mathrm{Na}_{\mathrm{v}} 1.7, \mathrm{Na}_{\mathrm{v}} 1.8$ and $\mathrm{Na}_{\mathrm{v}} 1.9$, respectively encoded by SCN9A, SCN10A and $S C N 11 A$, are preferentially expressed in the small diameter dorsal root ganglion neurons (DRGs) and their peripheral axons. They play important roles in generation and conduction of action potentials in the physiological pain pathway. ${ }^{5}$ In addition, $\mathrm{Na}_{\mathrm{v}} 1.7$ is present in sympathetic ganglion neurons of the peripheral autonomic nervous system. ${ }^{5}$

Gain-of-function VGSC variants or dysregulated VGSC expression can cause pathological pain states characterised by spontaneous and prolonged pain. ${ }^{6}$ A causal link between pathogenic SCN9A variants and multiple human pain syndromes has been reported. SCN9A variants that increase the excitability of DRG were initially found in inherited erythromelalgia (IEM), an autosomal dominant disorder characterised by episodic painful red discoloured extremities due to warm temperatures and exercise. ${ }^{78}$ Shortly thereafter, pathogenic $S C N 9 A$ variants were shown to be responsible for the episodic pain and autonomic features in the ocular, mandibular and sacral regions in paroxysmal extreme pain disorder (PEPD). ${ }^{9} 10$ Several years later, SCN9A gain-of-function variants were 
demonstrated in $28.6 \%(n=8 / 28)$ of a cohort of patients with skin biopsy-confirmed idiopathic pure SFN. ${ }^{11}$ Subsequently, pathogenic SCN10A ${ }^{12}$ and $S C N 11 A^{13}$ variants were found in in patients with SFN.

A follow-up study of 393 patients diagnosed with SFN, based on typical clinical features (neuropathic pain and autonomic complaints) in combination with an abnormal intraepidermal nerve fibre density (IENFD) in skin biopsy and/or abnormal temperature threshold testing (TTT), showed that 9.1\% $(\mathrm{n}=34 / 393)$ harboured an $S C N 9 A$ variant, $4.2 \%(\mathrm{n}=15 / 359)$ an SCN10A variant and $3.5 \%(\mathrm{n}=12 / 345)$ an $S C N 11 A$ variant. ${ }^{13} 14$

Over the past years our SFN-cohort has expanded to 1502 patients. Aims of the current study were to provide more precise data on SCN9A, SCN10A and SCN11A variant frequencies and a rationale for the genetic screening of patients with pure SFN and to compare the clinical features of patients with SFN with and without VGSC variants.

\section{METHODS}

\section{Study population and clinical characterisation}

The retrospective study was conducted at the Departments of Neurology and Clinical Genetics of the Maastricht University Medical Centre+ (Maastricht UMC+), Maastricht, The Netherlands, a tertiary national referral centre for patients with clinical symptoms of SFN. Between September 2009 and January 2017, 1502 adult patients (age $\geq 18$ years old) with SFN symptoms were examined in a structured day case setting. The following records were taken:

1. Demographic data; age of onset of complaints; duration of symptoms; altered pain sensation; presence of erythromelalgia symptoms, itch or cramps; influence of temperature, exercise or rest on pain; medical history and family history; neuropathic pain medication used at moment of presentation.

2. Neurological examination (muscle strength, pinprick sensation, vibration and position sense, tendon reflexes).

3. Nerve conduction studies (NCS; motor nerves: peroneal and tibial nerves to determine the compound muscle action potential amplitude, distal latency and conduction velocities; sensory nerves: ulnar and/or median and sural nerve to determine sensory nerve action potential amplitudes, distal latencies and conduction velocities).

4. Thermal threshold testing (TTT). ${ }^{15}$

5. Skin biopsy for determination of IENFD. ${ }^{16}$

6. Multiple questionnaires, including the Visual Analogue Scale to assess pain intensity ${ }^{17}$; Neuropathic Pain Scale (NPS) to evaluate 10 qualities of neuropathic pain ${ }^{18}$ and the SFN Symptom Inventory Questionnaire (SFN-SIQ) which includes 13 SFN specific symptoms. ${ }^{19}$

According to the international criteria, the diagnosis pure SFN was established when typical clinical symptoms were present in combination with a decreased IENFD in skin biopsy and/ or abnormal TTT, without signs of large nerve fibre damage on neurological examination and/or NCS. ${ }^{20}$ Other underlying diseases or use of medication were excluded as possible causes. To search for associated conditions, patients diagnosed with pure SFN underwent extensive blood analyses as described previously. ${ }^{21}$

\section{Variant screening}

Genomic DNA was extracted from whole blood using NucleoSpin8 Blood Isolation kit (Macherey-Nagel, Düren, Germany) according to manufacturer's instructions. Coding exons and exon-flanking intronic regions of SCN9A, SCN10A and SCN11A were amplified by PCR and sequenced by Sanger sequencing. Sequences were compared with reference sequence GRCh37. Variants detected were annotated according to guidelines of the Human Genome Variation Society (http://www.hgvs.org/ mutnomen/). Variants which were located in functional domain of the protein and/or at a highly conserved amino acid in mammalian paralogues/human VGSC orthologues were classified and reported according the Practice Guidelines of the Association for Clinical Genetic Science (ACGS) and recommendations of Waxman et al. ${ }^{22}{ }^{23}$ Cosegregation of (potentially) pathogenic variants with the disease was tested, if possible, in cases with a positive family history.

\section{Statistical analysis}

The primary analysis was the comparison of clinical variables between patients with pure SFN with and without VGSC variant. For categorical variables, the $\chi^{2}$ test was used or the Fisher's exact test when necessary. For continuous variables, the independent student's t-test was chosen. Equal variances between two groups were tested with the Levene's test. For these analyses, a significance level of 0.05 was used.

Posthoc analyses were performed to investigate whether differences between patients with specific VGSC variants and without variants were present. In total, six posthoc analyses per variable were executed. The analyses were performed in the same way as the primary analyses; however, the significance level was adjusted for multiple testing with the Bonferroni correction $(0.05 / 6)$. Therefore, posthoc analyses were compared with a significance level of 0.0083 . Missing values were not imputed or estimated.

\section{RESULTS}

\section{Patient characteristics}

The diagnosis of pure SFN was established in 1139 of 1502 patients $(75.8 \%)$ referred to our centre (figure 1). More females $(59.2 \%)$ were present than males. The mean age at presentation in our referral centre was 52.1 years (SD 13.2 years), with an age of onset of symptoms at 46 years (SD 14.6 years). In $25.9 \%$ of patients the diagnosis of pure SFN was based on the clinical picture in combination with both an abnormal IENFD and TTT, in $6.9 \%$ of the patients only the IENFD was abnormal, while in $67.2 \%$, solely an abnormal TTT was found.

In $61.1 \%(n=696)$ of patients with pure SFN, additional workup revealed no associated conditions. Autoimmune diseases were found in $21.7 \%(\mathrm{n}=247)$, glucose intolerance in $10.6 \%$ $(\mathrm{n}=121)$, vitamin B12 deficiency in $6.6 \%(\mathrm{n}=75)$, diabetes mellitus in $5.2 \%(\mathrm{n}=59)$, alcohol abuse in $2.7 \%(\mathrm{n}=31)$, chemotherapy in $2.2 \%(\mathrm{n}=25)$, monoclonal gammopathy of undetermined significance in $1.1 \%(\mathrm{n}=13)$ and haemochromatosis in $0.6 \%(\mathrm{n}=7)$ of patients, which is in line with our previous reports. ${ }^{21}$ Multiple associated conditions can be found within one patient.

\section{Genetic screening of SCN9A}

Among 1139 patients with pure, 28 different (potentially) pathogenic heterozygous $S C N 9 A$ variants were detected in 58 patients (5.1\%, figure 1 and table 1$)$. Six variants have already been published as pathogenic, ${ }^{11}{ }^{24-27}$ one variant as probably pathogenic, ${ }^{11}$ and two variants as risk factor. ${ }^{23}$ Eighteen variants were novel and classified as possibly pathogenic $(\mathrm{n}=3)$ or of uncertain clinical significance (VUS, $\mathrm{n}=15$; table 1). Eleven SCN9A variants were found in $>1$ patient. Nine patients harboured more than 


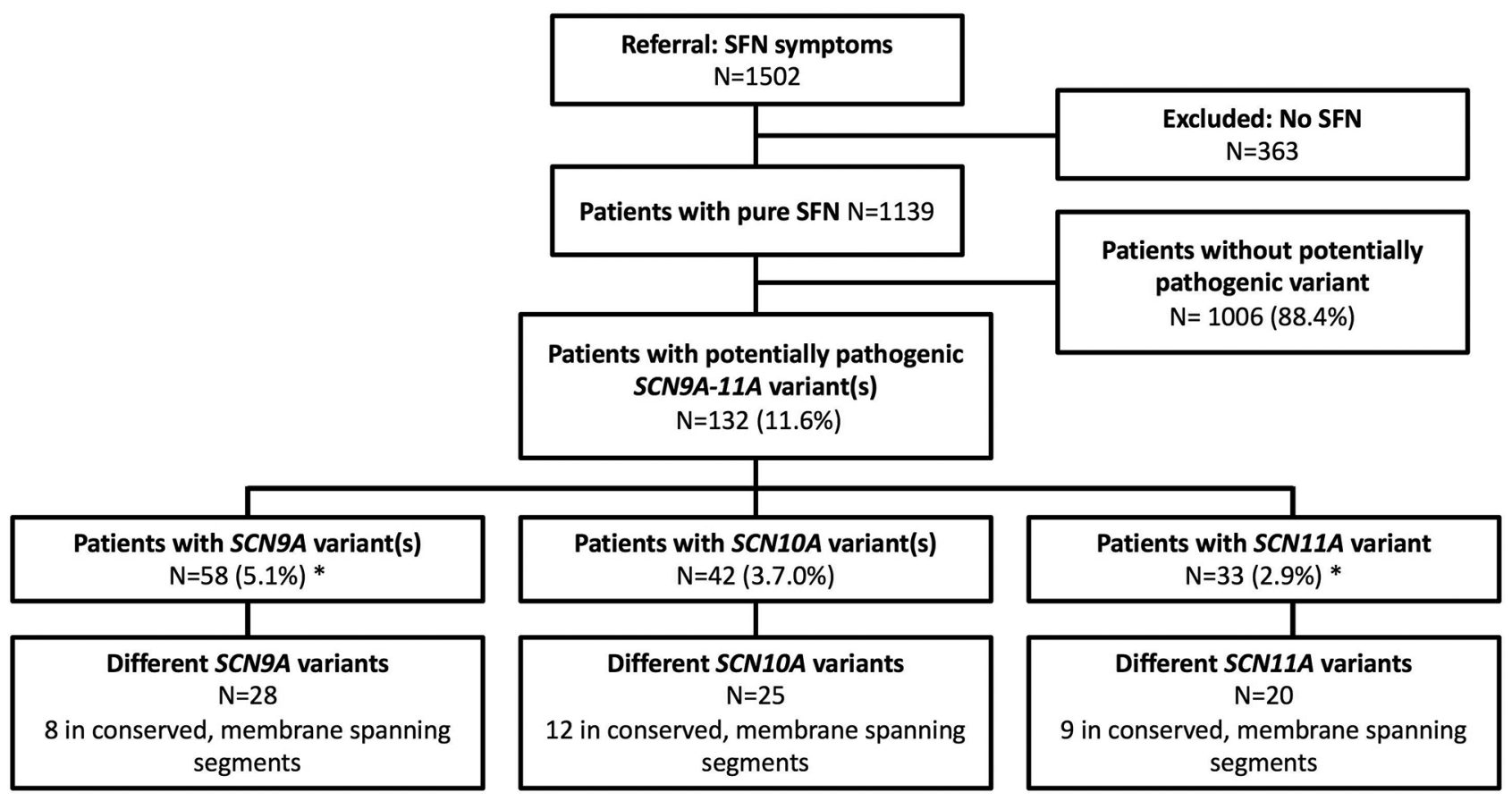

Figure 1 Patients with SFN analysed for potentially pathogenic SCN9A, SCN10A and SCN11A variants in the Maastricht University Medical Center+. Diagnosis of pure SFN was made according to the international criteria, by the clinical symptoms combination with an abnormal intraepidermal nerve fibre density in skin biopsy and/or abnormal temperature threshold testing. ${ }^{218}$ Genetic screening of SCN9A, SCN10A and SCN11A was performed with Sanger sequencing. Variants which were located in functional domain of the protein and/or at a highly conserved amino acid in mammalian paralogues/human VGSC orthologues were classified according to the practice guidelines of the Association for Clinical Genetic Science and recommendations of Waxman. ${ }^{20} 21$ Patients in this study were included between September 2009 and January 2017. *One patient was heterozygous for two SCN9A variants and one SCN11A variant. SFN, small fibre neuropathy.

one variant in SCN9A (table 1). Finally, one patient was heterozygous for two SCN9A VUSs, c. $1555 \mathrm{G}>\mathrm{A}$ and c.2271G $>\mathrm{A}$ and the pathogenic $S C N 11 A$ c. 3473 T $>$ C variant.

For nine variants cell electrophysiology showed a gain-offunction of the $\mathrm{Na}_{\mathrm{v}} 1.7$ channel. ${ }^{11}{ }^{24-29}$ Cosegregation with pain in the family was demonstrated for six variants, was inconclusive for three variants and not supportive for two variants (table 1).

Nine (potentially) pathogenic SCN9A variants detected in our cohort of patients with pure SFN have been reported in patients with IEM, PEPD, paroxysmal itch, painful diabetic neuropathy (PDN) and Dravet syndrome. ${ }^{30-34}$ Two patients with SFN, positive for one of these SCN9A variants, had a history consistent with erythromelalgia (variant c.554G>A), two patients with SFN suffered from diabetes mellitus (one patient with variant c. $1552 \mathrm{G}>\mathrm{T}$ and one patient with variant c. $2215 \mathrm{~A}>\mathrm{G}$ ) and three patients with SFN complained of itch (variant c.2215A $>G$ ). None of the other patients carrying $\geq 1$ of these $S C N 9 A$ variants were positive for erythromelalgia, PEPD, paroxysmal itch, PDN or Dravet syndrome.

The clinical features of each individual patient harbouring (potentially) pathogenic SCN9A variants are shown in the online supplementary table 1 .

\section{Genetic screening of SCN10A}

In SCN10A, 25 different (potentially) pathogenic heterozygous variants were detected in 42 patients with pure SFN $(3.7 \%$, $\mathrm{n}=45 / 1,139$, figure 1 and table 2 ). One variant was already published as pathogenic ${ }^{35}$ and three variants as probably pathogenic $^{1236}$ Twenty-one variants were novel for SFN and classified as probably pathogenic $(n=2)$, possibly pathogenic $(n=2)$ or VUS ( $n=17$; table 2). Five $S C N 10 A$ variants were present in $>1$ patient. Two patients harboured two SCN10A variants. For three variants, cell electrophysiology showed a gain-of-function of the $\mathrm{Na}_{\mathrm{v}} 1.8$ channel and for one variant, DRG neuron hyperexcitability was seen (table 2). ${ }^{123536}$ Cosegregation tested for three patients was only positive for one variant (table 2).

Eight (potentially) pathogenic SCN10A variants detected in our cohort of patients with pure SFN have been reported in patients with Brugada syndrome $(\mathrm{BrS})$, atrial fibrillation (AF), sudden infant death syndrome (SIDS), Lennox-Gastaut syndrome (LGS), febrile infection-related epilepsy syndrome (FIRES) and autism. ${ }^{37-40}$ Only the patients with SFN with variant c. $41 \mathrm{G}>\mathrm{T}$ had arrhythmia. The other previously reported conditions were not seen in our cohort of patients with $\geq 1$ SCN10A variants.

The individually clinical data of the 42 patients with pure SFN with (potentially) pathogenic SCN10A variants are shown in the online supplementary table 2 .

\section{Genetic screening of SCN11A}

We found 20 different (potentially) pathogenic heterozygous variants in 33 patients with pure SFN (2.9\%, $n=33 / 1,139$, figure 1 and table 3$)$. Three variants were already published as probably pathogenic, ${ }^{13} 41$ and one variant as possibly pathogenic and five variants as VUS. ${ }^{13}$ Eleven variants were novel and classified as possibly pathogenic $(n=5)$ or VUS $(n=6$; table 3$)$. Six $S C N 11 A$ variants were detected in $>1$ patient. Only one patient was heterozygous for two SCN9A VUSs (c.1555G $>$ A and c. $2271 \mathrm{G}>\mathrm{A}$ ) and the pathogenic $S C N 11 A$ c. $3473 \mathrm{~T}>\mathrm{C}$ variant.

Cell electrophysiology showed a gain-of-function of three SCN11A variants, ${ }^{13} 41$ while a loss-of-function of the $\mathrm{Na}_{\mathrm{v}} 1.9$ channel was seen for one variant. ${ }^{41}$ Cosegregation was tested for two variants and only supportive for one (table 3). All 25 


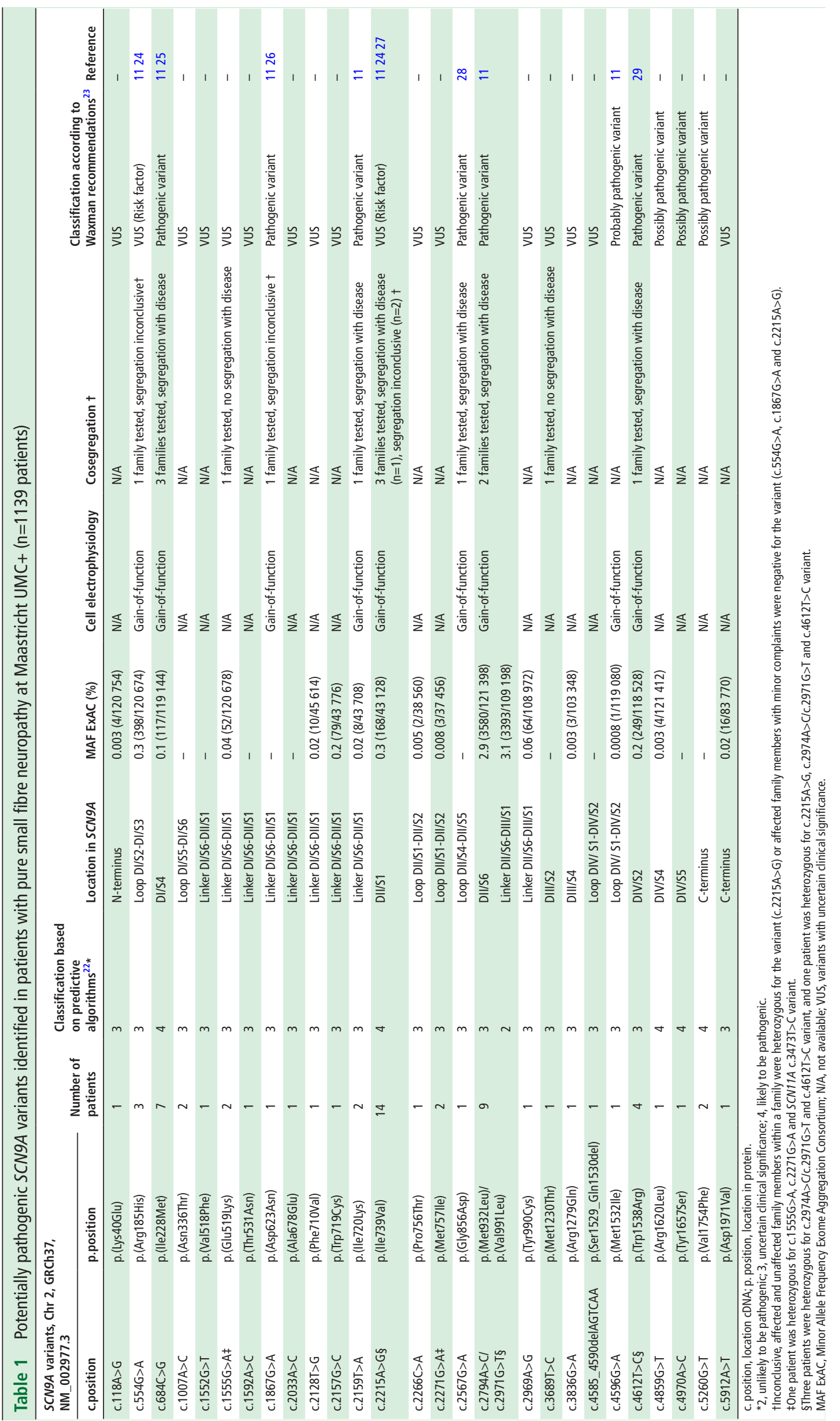




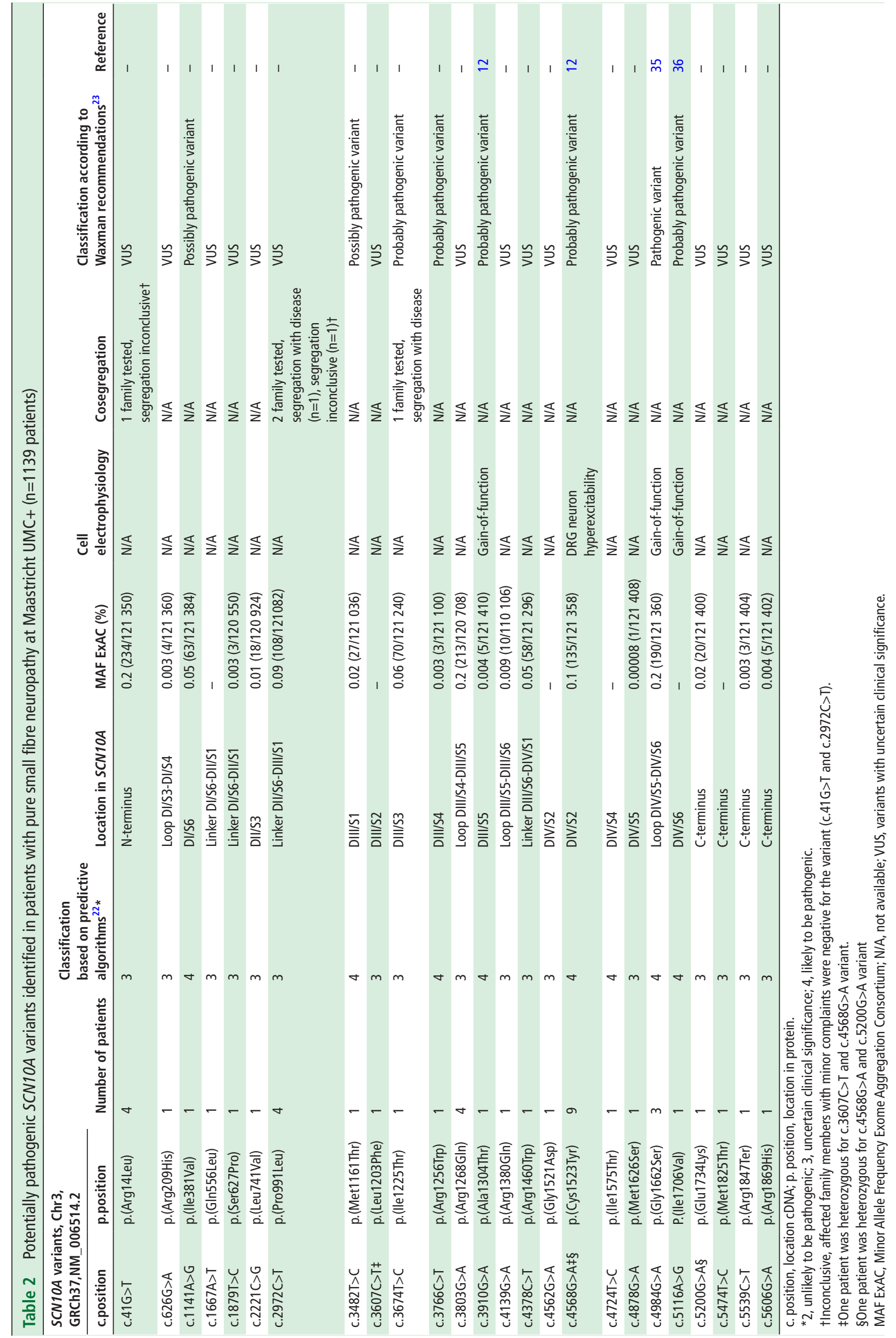




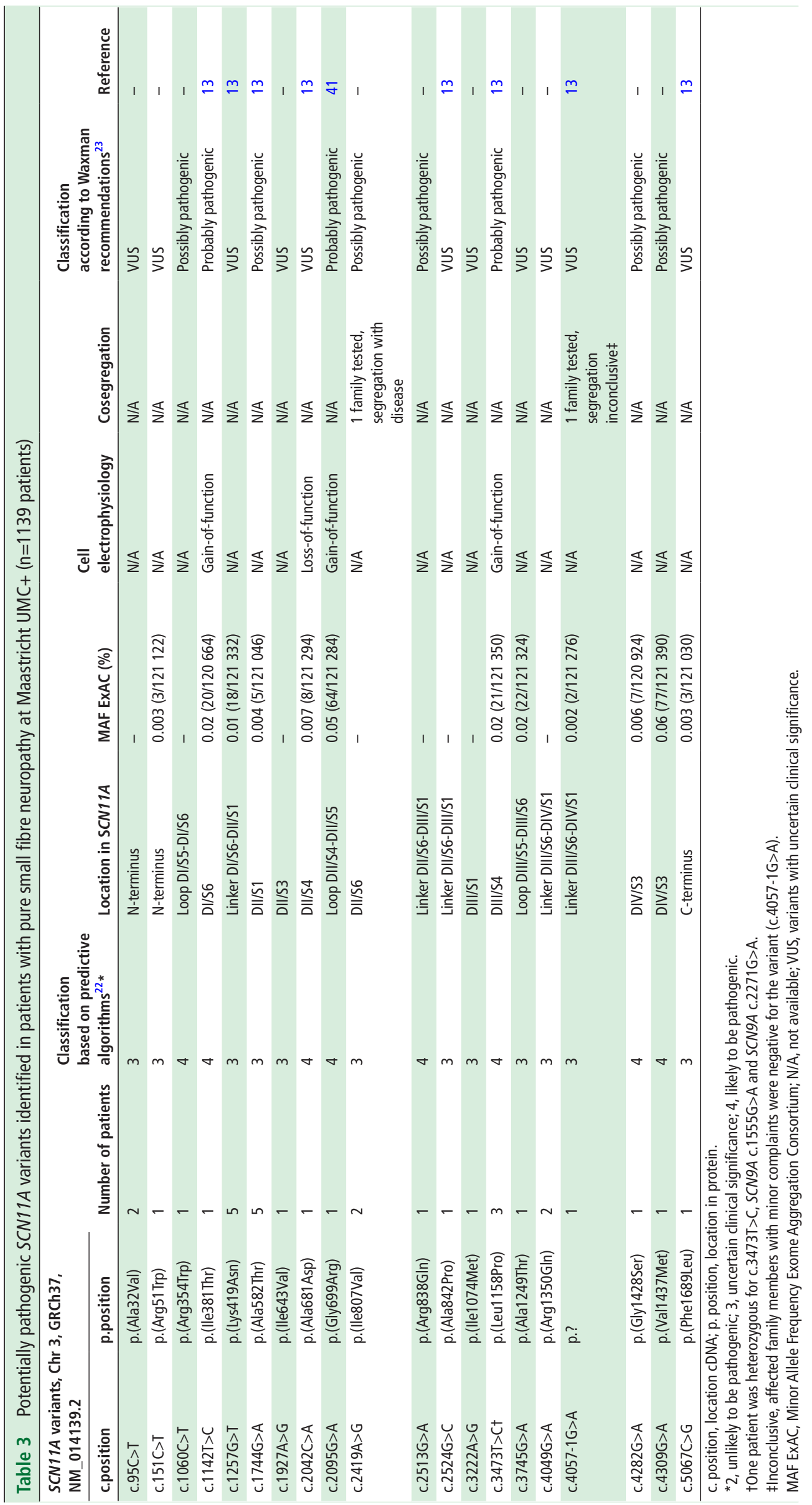


(potentially) pathogenic SCN11A variants detected in our cohort were specific for SFN.

The clinical features per patient harbouring (potentially) pathogenic SCN11A variant are shown in the online supplementary table 3 .

\section{Patients with pure SFN with or without VGSC variant}

The number of patients with SFN with a VGSC variant and a decreased IENFD was not significantly higher than that of patients without a VGSC variant $(37.9 \%$ vs $32.6 \%$; $=0.328)$. Furthermore, in both groups TTT was almost equally abnormal (92.4\% with VGSC variant vs 93.2\% without VGSC variant; $\mathrm{p}=0.741)$. Patients that harbour an $S C N 9 A$ variant reported significantly more often erythromelalgia-like symptoms compared with patients with an SCN10A variant or without VGSC variant $(43.9 \%$ vs $16.7 \% ; \mathrm{p}=0.004 \%$ and $43.9 \%$ vs $26.4 \% ; p=0.004)$. The proportion of patients with SFN that experienced an aggravation of the pain by warm temperature was significantly higher in those with a VGSC variant compared with those without VGSC variant $(45.2 \%$ vs $30.9 \%$; $\mathrm{p}=0.014)$. No differences were seen in other symptoms, obtained by history taking and various questionnaires (figure 2 and figure 3). In case patients were harbouring multiple VGSC variants, in the same channel or in different channels, the type of complaints and severity was similar.

In patients with a VGSC variant, family history for SFN-related symptoms was more frequently positive than in the other patients with pure SFN $(33.9 \%$ vs $24.6 \%$; $p=0.027$; online supplementary table 4). In $15.1 \%(n=66 / 436)$ of patients with pure SFN with an underlying condition a (potentially) pathogenic VGSC variant was found. In the 132 patients with SFN with a VGSC variant the following underlying conditions were demonstrated: in 22.0\% $(\mathrm{n}=29)$ an immunological disease, in $6.8 \%(\mathrm{n}=9)$ glucose intolerance, in 5.3\% $(\mathrm{n}=7)$ vitamin $\mathrm{B} 12$
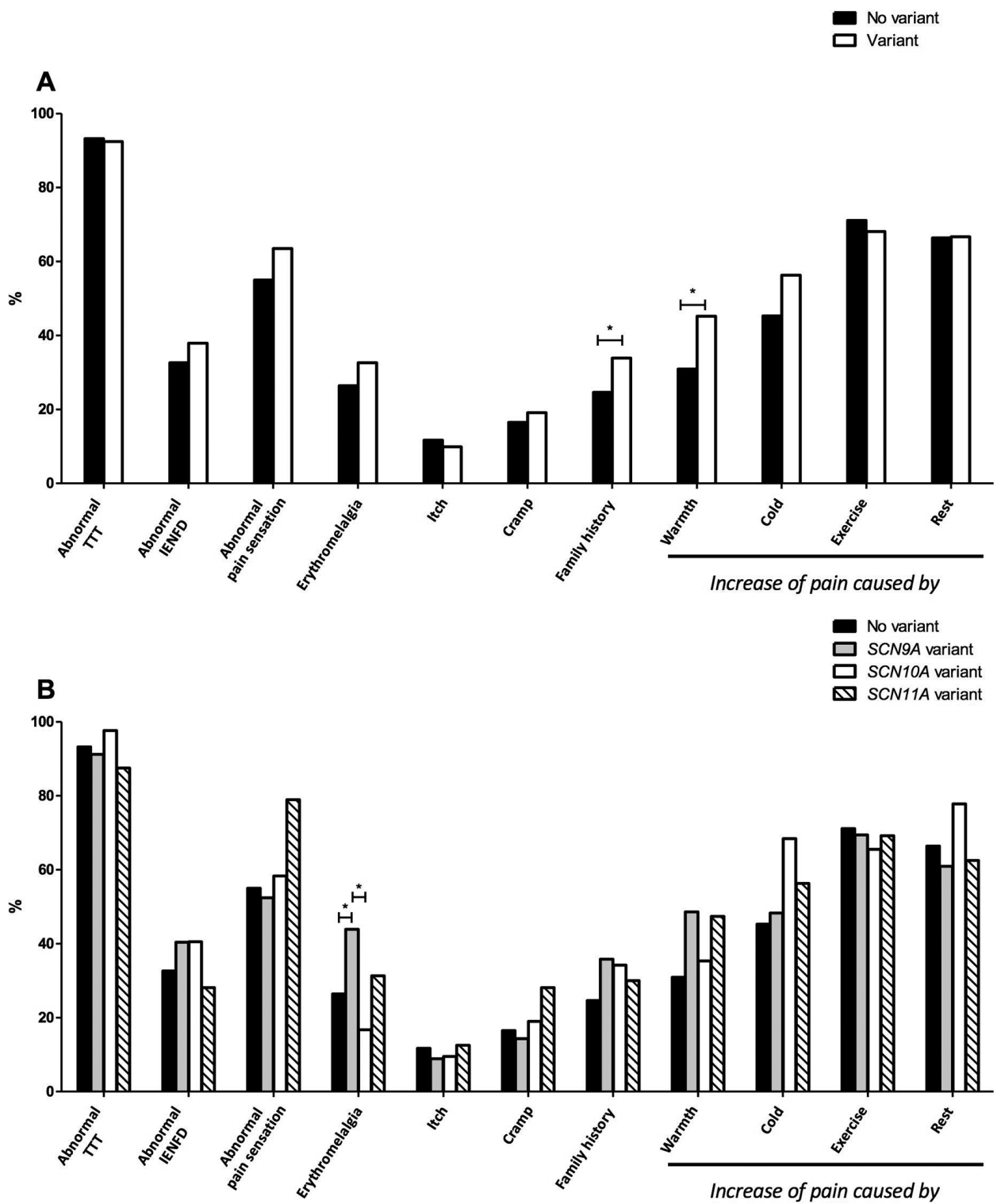

Figure 2 Clinical features of patients with pure small fibre neuropathy with or without (potentially) pathogenic voltage-gated sodium channel variant. (A) Patients with pure SFN without VGSC variant versus all patients with pure SFN with VGSC variant. (B) patients with pure SFN without VGSC variant versus patients with pure SFN with SCN9A variant or SCN10A variant or SCN11A variant. ${ }^{*}<0.0083$. Erythromelalgia symptoms are significantly more frequently reported in patients with pure SFN with a (potentially) pathogenic SCN9A variant compared to patients without VGSC variant or with an SCN10A variant. For exact data, see online supplementary table 4. IENFD, intraepidermal nerve fibre density; TTT, temperature threshold testing. 

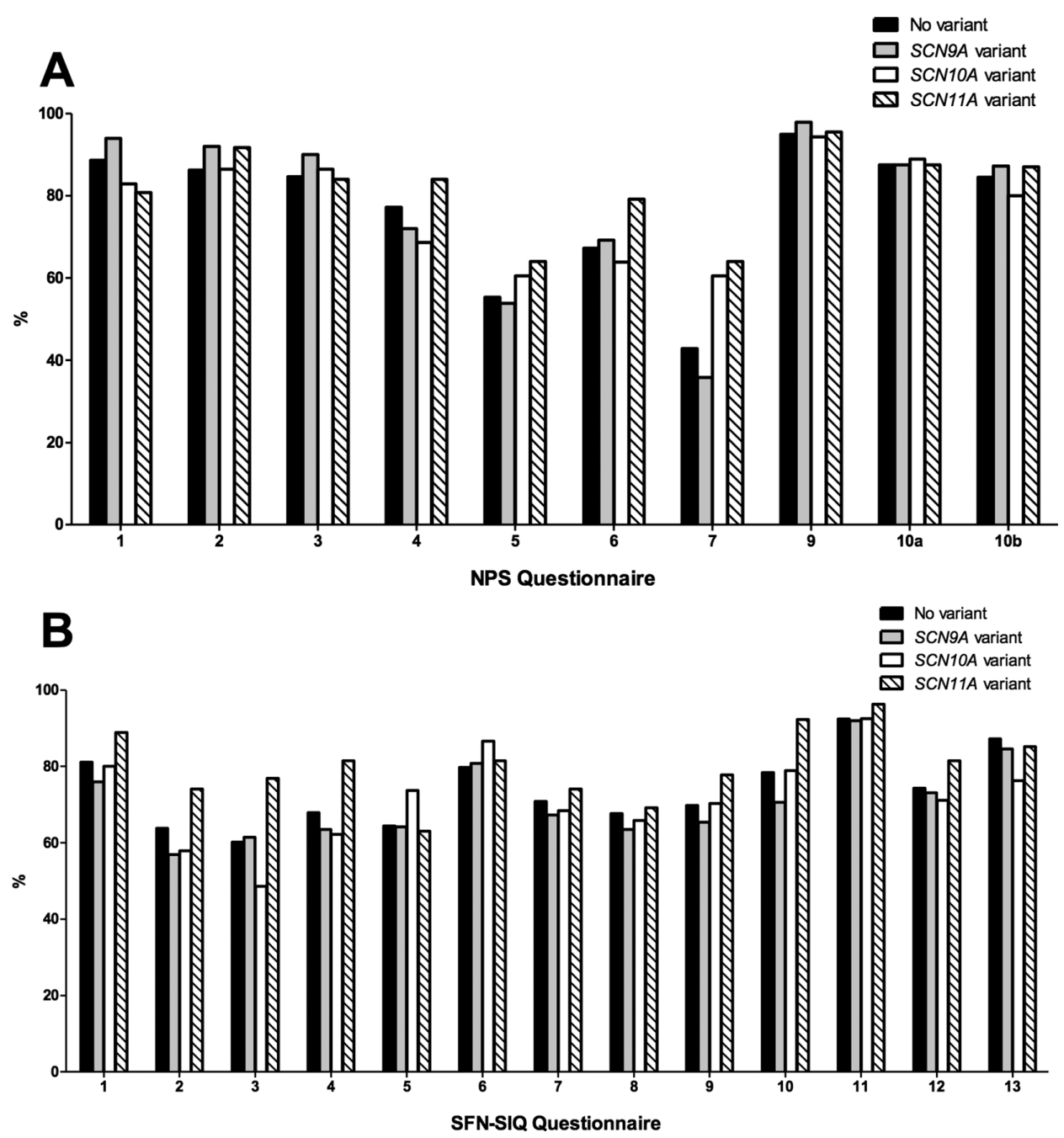

Figure 3 Questionnaires of patients with pure small fibre neuropathy with or without (potentially) pathogenic voltage-gated sodium channel variant. (A) NPS pain qualities: $1=$ =severity; 2 =sharpness; 3 =hotness; $4=$ dullness; $5=$ coldness; $6=$ =sensitivity; $7=$ itchiness; $9=$ unpleasantness; $10 \mathrm{a}=$ intensity deep pain; $10 \mathrm{~b}=$ intensity surface pain. Each item is scored on an 11-point scale $(0=$ not applicable to the experienced pain and $10=$ in the most severe form applicable to the experienced pain). An NPS score $>3$ is considered as a relevant pain quality. (B) SFN-SIQ symptoms: $1=$ altered sweating pattern; $2=$ diarrhoea; $3=$ constipation; $4=$ micturation problems; $5=$ dry eyes; $6=$ dry mouth; $7=$ orthostatic dizziness; $8=$ palpitations; $9=$ hot flashes; $10=$ sensitive skin legs; 11 =burning feet; $12=$ intolerance for sheets; $13=$ restless legs. The answer options of the SFN-SIQ include 'never=1', 'sometimes=2', 'often=3' and 'always $=4$ '. A symptom is considered to be present when the score is $>1$. No statistically significant differences in experienced pain qualities and small fibre neuropathy symptoms were found between pure small fibre neuropathy patients with or without (potentially) pathogenic voltage-gated sodium channel variant. For exact data, see online supplementary table 4. NPS, Neuropathic Pain Scale; SFN-SIQ, small fibre neuropathy inventory questionnaire.

deficiency, in $3.0 \%(\mathrm{n}=4)$ diabetes mellitus, in $2.3 \%(\mathrm{n}=3)$ alcohol abuse, in $0.8 \%(\mathrm{n}=1)$ a history of chemotherapy and in $0.8 \%(\mathrm{n}=1)$ a monoclonal gammopathy of undetermined significance. The number of patients per specific underlying condition was too small to study potential relationships between these conditions and particular VGSC variants.

As all of the patients in our cohort suffered from painful SFN and no patients with painless SFN were included, it was not possible to investigate if the presence of VGSC variants in patients with an associated condition is related to the development of pain. Since this study had a retrospective design, it was not possible to collect data about the use of pain medication in a standardised way to provide reliable information on the response to treatment. However, the data on pain features and intensity, indirectly suggest the poor efficacy of the drugs (online supplementary tables $1-3)$.

\section{DISCUSSION}

In our retrospective cohort, 132 of 1139 (11.6\%) patients with pure SFN harbour potentially pathogenic heterozygous variants in SCN9A, SCN10A and/or SCN11A. SCN9A variants were found more frequently $(5.1 \%, \mathrm{n}=58 / 1139$ patients) than $S C N 10 A$ $(3.7 \%, \mathrm{n}=41 / 1139$ patients) and $\operatorname{SCN} 11 \mathrm{~A}(2.9 \%, \mathrm{n}=38 / 1139$ patients) variants. Fifty variants were novel for SFN and classified as probably pathogenic $(n=2)$, possibly pathogenic $(n=10)$ or VUS ( $\mathrm{n}=38$ ). In this cohort, erythromelalgia showed a significant relationship with the presence of SCN9A variants. Furthermore, warmth-induced pain was significantly increased with the presence of potentially pathogenic VGSC variants. Other clinical features of pure SFN, such as abnormal TTT, abnormal IENFD, abnormal pain sensation, itch, cramp and cold-induced, exercise-induced and rest-induced pain, were not significant different for patients with and without VGSC variants (figure 2). Also, the 
NPS and SFN-SIQ revealed comparable results for patients with and without VGSC variants (figure 3 ).

The frequencies of variants in the SCN10A and SCN11A genes in our patients with pure SFN are slightly lower than those reported before, respectively, $4.2 \%-4.8 \%$ and $3.5 \%-$ $3.8 \% .^{131421}$ For SCN9A, however, the frequency has decreased over the years. At first, eight gain-of-function variants were identified in 28 subjects (28.6\%) with biopsy-confirmed idiopathic pure SFN. ${ }^{11}$ Subsequently, in the cohort of 393 consecutive patients diagnosed with SFN, 17 potentially pathogenic variants were found in 34 patients (9.1\%). ${ }^{13} 14$ Then, we reported in an extended cohort of 921 patients diagnosed with idiopathic pure SFN, 78 patients have $\geq 1$ potentially pathogenic $S C N 9 A$ variants $(8.5 \%),{ }^{21}$ and here we report 58 subjects with $\geq 1$ potentially pathogenic $S C N 9 A$ variants in 1139 patients with pure SFN (5.1\%). The decline in frequency for SCN9A in the expanded cohort can be explained by less stringent inclusion criteria for the current cohort, more stringent variant classification criteria, extension of functional data obtained by cell electrophysiology and data of cosegregation analysis. For instance, variants with no change in channel function and/or cosegregation with the disease in affected family members, like c.3734A $>$ G (p.Asn1245Ser) and c.3799C $>$ G (p.Leu1267Val), were classified as unlikely to be pathogenic in the current study, while they were classified as VUS with frequencies, respectively, of $1.5 \%$ and $1.3 \%$ in the cohort of 393 patients with SFN, ${ }^{13} 14$ and $1.1 \%$ and $0.9 \%$ in the cohort of 921 patients with idiopathic pure SFN.

To date, only one other cohort of patients with painful neuropathy $(\mathrm{n}=217)$ has been tested for SCN9A, SCN10A and SCN11A gene variations. ${ }^{42}$ In this cohort, the number of patients with $\geq 1$ low-frequency (minor allele frequency $(\mathrm{MAF})<5 \%$ in the NHLBI Exome Sequencing Project Exome Variant Server, European American (EVS-EA) population) missense variant in SCN9A, SCN10A and SCN11A was respectively 25\%, 21\% and $13 \%$. From these low-frequency missense variants, $8.7 \%$ SCN9A $(n=19 / 217), \quad 0.9 \% \quad S C N 10 A \quad(n=2 / 217)$ and $0.9 \%$ SCN11A $(n=2 / 17)$ variants have been previously reported in patients with IEM, SFN or PDN, including SCN9A variant c. $3734 \mathrm{~A}>\mathrm{G} \quad(\mathrm{n}=7 / 217,3.2 \%)$ and c. $3799 \mathrm{C}>\mathrm{G} \quad(\mathrm{n}=1 / 217$, $0.5 \%) .{ }^{42}$ Compared with our cohort, the incidence of potentially pathogenic variants in the 217 patients with painful neuropathy was $\sim 4-5$-fold higher. The discrepancies in frequencies of reported variants between both cohorts are mainly caused by different variant filtering strategies (ie, MAF $<5 \%$ vs $<1 \%$ ) and variant classification approaches (ie, all missense mutations vs highly conserved missense mutation). Different patient inclusion criteria and used sequencing platforms may also have an effect the frequencies of variants detected.

Nine (potentially) pathogenic SCN9A variants detected in our cohort of patients with pure SFN have been reported as disease-causing variants in other pain phenotypes and Dravet syndrome. ${ }^{30-34}$ Multigenerational segregation with the disease in SFN families and/or functional testing in DRG neurons by cell electrophysiology support that these variants are causative for SFN (table 1). As patients with SFN share clinical features with other pain-phenotypes, it is not surprising that these variants are reported for SFN and IEM, paroxysmal itch and painful diabetic neuropathy. Features of Dravet syndrome have not been seen in our cohort, and no abnormal pain sensation have been reported for patients with Dravet syndrome and a (potentially) pathogenic SCN9A variant. ${ }^{43}$ For SCN10A variants, eight (potentially) pathogenic variants have been report as disease-causing in $\mathrm{BrS}$, AF, SIDS, LGS, FIRES and autism. ${ }^{37-40}$ Multigenerational segregation with the disease in SFN families and/or functional testing in DRG neurons by cell electrophysiology indicate that the majority of the variants are causative for SFN (table 2). Variant c.41G > T, p.(Arg14Leu), which has been described in patients with $\mathrm{BrS}$ and $\mathrm{AF},{ }^{37} 38$ was identified four times in our cohort of patients with SFN. Only one patient had SFN and arrhythmia. SIDS, LGS, FIRES and autism have not been seen in our patients with pure SFN. For SCN11A, none of potentially pathogenic variants identified in the current study have been associated with other inherited disorders. Taken together, these findings suggest that one variant can produce multiple different disease outcomes, depending on cell-type-specific expression ${ }^{112425}$ presence of additional disease-causing variants or modifiers ${ }^{23}$ and/ or additional underlying conditions (eg, diabetes mellitus or vitamin B12 deficiency). ${ }^{21}$

For variants where segregation with disease in multigenerations was confirmed, this should be considered supporting, though not definite evidence for pathogenicity. A definite conclusion would require at least 10 meioses, which is generally not the case. In this study, cosegregation of the variant with disease was only tested for 15 potentially pathogenic variants in 20 families, because most families were too small to test segregation with disease properly or the proband was not in contact with their relatives.

About two-third of the potentially pathogenic SCN9A variants identified in our cohort of patients with pure SFN have been localised to domain I (DI) and II (DII) and the intracellular linker between DI-DII and DII-domain III (DIII). This is in contrast with our findings for SCN10A, where approximately $70 \%$ of the SCN10A variants were localised to DIII and domain IV (DIV), the intracellular linker between DIII-DIV and C-terminus of the protein. For SCN11A, the distribution of potentially pathogenic variants was all across the gene. No possible hotspots were identified in this gene.

Patch clamp studies have shown that SCN9A variants associated with SFN produce gain-of-function channel changes, ranging from impaired slow-inactivation to depolarised slow-inactivation and fast-inactivation, and induce DRG neurons hyperexcitability. ${ }^{11}$ 24-29 Compared with PEPD, where most SCN9A variants were located in the intracellular linker between DIII-DIV and intracellular loop linking segments S4-S5 of DIII and DIV, effects on fast-inactivation of SFN SCN9A variants were relatively mild. IEM SCN9A variants exhibit hyperpolarised activation or enhanced ramp currents and were mainly localised to transmembrane segment S4, S5 and S6 and the intracellular loop linking segments S4-S5. ${ }^{44}$ Functional IEM characteristics were not demonstrated for SFN SCN9A variants. Although most potentially pathogenic SCN9A variants in this cohort were localised to DI and DII and the intracellular linkers DI-DII and DII-III, it is still unclear how this type of $\mathrm{Na}_{\mathrm{v}} 1.7$ channel dysfunction causes SFN. However, certain SFN SCN9A variants have been shown to impair regeneration and/or degeneration of sensory axons, suggesting that enhanced sodium channel activity and reverse $\mathrm{Na}-\mathrm{Ca}$ exchange may contribute to a decrease in length of peripheral sensory axons. ${ }^{45}$

Besides SCN9A, variants in SCN10A and SCN11A have been shown to participate in the pathophysiology of SFN. DRG neurons expressing SCN10A or SCN11A mutant channels exhibit increased excitability and abnormal spontaneous firing activity. $^{12} 13353641$ One SCN10A variant and nine SCN11A variants have been associated with other inherited pain disorders. ${ }^{46-50}$ Although different cell electrophysiology properties were seen for several of these varians, ${ }^{12} 13$ 35-374146 functional data for SCN10A and SCN11A variants are too limited to correlate channel phenotype with clinical phenotype. 
In conclusion, in this cohort of 1139 patients with pure SFN, the overall frequency of potentially pathogenic SCN9A, $S C N 10 A$ and SCN11A variants is $11.6 \%$. Erythromelalgia and warmth-induced pain were the only SFN-related clinical features that showed a significant relationship with the presence of VGCS variants. As genetic screening for all patients with pure SFN is debatable, we believe that in the future, as the number of well-characterised variants of $\mathrm{Na}_{\mathrm{v}}$ channels increases, and an interexpert concordance on variant classification is reached, the utility of genetic screening for clinical care will rise and tailored treatments with specific sodium channel blockers can be developed. Furthermore, we have seen that certainty about the origin of symptoms as well as genetic counselling by which the patient and relatives are informed about the possibility of developing and transmitting the condition, is of great importance for patients with pure SFN. Therefore, genetic screening of SCN9A, SCN10A and SCN11A should be considered for patients with pure SFN, independently of clinical features or underlying conditions.

\section{Author affiliations}

'Department of Genetics and Cell Biology, Clinical Genomics Unit, Maastricht University, Maastricht, The Netherlands

${ }^{2}$ MHeNs School of Mental Health and Neuroscience, Maastricht University, Maastricht, The Netherlands

${ }^{3}$ Department of Neurology, Maastricht University Medical Centre+, Maastricht, The Netherlands

${ }^{4}$ Department of Medical Laboratory Sciences, Jordan University of Science and Technology, Irbid, Jordan

${ }^{5}$ Neuroalgology Unit, IRCCS Fondazione Istituto Neurologico "Carlo Besta", Milan, Italy

${ }^{6}$ Department of Neurology and Center for Neuroscience and Regeneration Research, Yale University School of Medicine, New Haven, Connecticut, USA

${ }^{7}$ Centre for Neuroscience and Regeneration Research, Veterans Affairs Medical Center, West Haven, Connecticut, USA

${ }^{8}$ Department of Biomedical and Clinical Sciences "Luigi Sacco", University of Milan, Milan, Italy

${ }^{9}$ Department of Neurology, St. Elisabeth Hospital, Willemstad, Curaçao

${ }^{10}$ Department of Clinical Genetics, Maastricht University Medical Centre, Maastricht, The Netherlands

Correction notice Since this paper was first published online a funding statement has been added to the proof.

Contributors Study concept and design: IE, MS, JGJH, BTADG, HJMS, ISJM, CGF, MMG. Acquisition, analysis or interpretation of the data: all authors. Statistical analysis: IE, MS, BTADG, PL, ISJM. Drafting of the manuscript: IE, MS, JH, BTADG, MMG. Review of the manuscript: RA, MM, JV, HJMS, SGW, GL, ISJM, CGF. Study supervision: JGJH, HJMS, ISJM, CGF, MMG.

Funding This work was supported in part by a grant from European Union's Horizon 2020 research and innovation programme Marie Sklodowska-Curie grant for PAIN-Net, Molecule-to-man pain network (grant no. 721841).

Competing interests JGJH reports personal fees from Pfizer Inc. (travel funding and speakers' honorarium) and grants from Prinses Beatrix Spierfonds (W.OK1709), outside the submitted work. SGW reports grants from European Union's Horizon 2020 research and innovation programme Marie Sklodowska-Curie grant for PAIN-Net, Molecule-to-man pain network (grant no. 721841) and European Union 7th Framework Programme (grant no. 602273) for the PROPANE study and was supported in part by the Rehabilitation Research and Development Service and Biomedical Laboratory Research Service, Department of Veterans Affairs, outside the submitted work. GL reports grants from European Union's Horizon 2020 research and innovation programme Marie Sklodowska-Curie grant for PAIN-Net, Moleculeto-man pain network (grant no. 721841) and European Union 7th Framework Programme (grant $n^{\circ} 602273$ ) for the PROPANE study and participates in Steering committees/advisory boards for studies in small fibre neuropathy of Biogen/ Convergence, Vertex and Chromocell, outside the submitted work. ISJM reports grants from Talecris Talents program, GSB CIDP Foundation International, Prinses Beatrix Spierfonds (W.OR12-01, W.OR15-25) and European Union 7th Framework Programme (grant no. 602273), participates Steering committees of the Talecris ICE Study, LFB, CSL Behring, Novartis, Grifols and Octapharma, serves on the editorial board of the Journal of Peripheral Nervous system and is a member of the Inflammatory Neuropathy Consortium (INC) and Peripheral Nerve Society, outside the submitted work. CGF reports grants from European Union's Horizon 2020 research and innovation programme Marie Sklodowska-Curie grant for PAIN-Net, Molecule-to-man pain network (grant no. 721841), European Union 7th Framework Programme (grant $n^{\circ} 602273$ ) for the PROPANE study, Prinses Beatrix Spierfonds (W.OR12-01, W.OR15-25), Grifols and Lamepro for a trial on IVIg in small fibre neuropathy and participates in Steering committees/advisory boards for studies in small fibre neuropathy of Biogen/Convergence, Vertex and Chromocell, outside the submitted work. Other authors have no conflicts of interests to declare.

Patient consent Not required.

Ethics approval This study was approved by the Medical Ethics Committee and Board of Directors of the Maastricht UMC+.

Provenance and peer review Not commissioned; externally peer reviewed.

\section{REFERENCES}

1 Treede RD, Jensen TS, Campbell JN, et al. Neuropathic pain: redefinition and a grading system for clinical and research purposes. Neurology 2008;70:1630-5.

2 Hoeijmakers JG, Faber CG, Lauria G, et al. Small-fibre neuropathies--advances in diagnosis, pathophysiology and management. Nat Rev Neurol 2012;8:369-79.

3 Finnerup NB, Attal N, Haroutounian S, et al. Pharmacotherapy for neuropathic pain in adults: a systematic review and meta-analysis. Lancet Neurol 2015;14:162-73.

4 Brouwer BA, de Greef BT, Hoeijmakers JG, et al. Neuropathic pain due to small fiber neuropathy in aging: current management and future prospects. Drugs Aging 2015;32:611-21.

5 Catterall WA, Goldin AL, Waxman SG. International Union of Pharmacology. XLVII. Nomenclature and structure-function relationships of voltage-gated sodium channels. Pharmacol Rev 2005;57:397-409.

6 Dib-Hajj SD, Cummins TR, Black JA, et al. Sodium channels in normal and pathological pain. Annu Rev Neurosci 2010;33:325-47.

7 Dib-Haji SD, Rush AM, Cummins TR, et al. Gain-of-function mutation in Nav1.7 in familial erythromelalgia induces bursting of sensory neurons. Brain 2005:128-1847-54.

8 Spillane J, Kullmann DM, Hanna MG. Genetic neurological channelopathies: molecular genetics and clinical phenotypes. J Neurol Neurosurg Psychiatry 2016;87:37-48.

9 Fertleman $C R$, Ferrie CD. What's in a name--familial rectal pain syndrome becomes paroxysmal extreme pain disorder. J Neurol Neurosurg Psychiatry 2006;77:1294-5.

10 Fertleman CR, Baker MD, Parker KA, et al. SCN9A mutations in paroxysmal extreme pain disorder: allelic variants underlie distinct channel defects and phenotypes. Neuron 2006;52:767-74.

11 Faber CG, Hoeijmakers JG, Ahn HS, et al. Gain of function Nav1.7 mutations in idiopathic small fiber neuropathy. Ann Neurol 2012;71:26-39.

12 Faber CG, Lauria G, Merkies IS, et al. Gain-of-function Nav1.8 mutations in painful neuropathy. Proc Natl Acad Sci U S A 2012;109:19444-9.

13 Huang J, Han C, Estacion M, et al. Gain-of-function mutations in sodium channel $\mathrm{Na}(\mathrm{v}) 1.9$ in painful neuropathy. Brain 2014;137(Pt 6):1627-42.

14 Brouwer BA, Merkies IS, Gerrits MM, et al. Painful neuropathies: the emerging role of sodium channelopathies. J Peripher Nerv Syst 2014;19:53-65.

15 Yarnitsky D, Sprecher E. Thermal testing: normative data and repeatability for various test algorithms. J Neurol Sci 1994;125:39-45.

16 Lauria G, Bakkers M, Schmitz C, et al. Intraepidermal nerve fiber density at the distal leg: a worldwide normative reference study. J Peripher Nerv Syst 2010;15:202-7.

17 Maxwell C. Sensitivity and accuracy of the visual analogue scale: a psycho-physical classroom experiment. Br J Clin Pharmacol 1978;6:15-24.

18 Galer BS, Jensen MP. Development and preliminary validation of a pain measure specific to neuropathic pain: the Neuropathic Pain Scale. Neurology 1997;48:332-8.

19 Brouwer BA, Bakkers M, Hoeijmakers JG, et al. Improving assessment in small fiber neuropathy. J Peripher Nerv Syst 2015;20:333-40.

20 Tesfaye S, Boulton AJ, Dyck PJ, et al. Diabetic neuropathies: update on definitions, diagnostic criteria, estimation of severity, and treatments. Diabetes Care 2010;33:2285-93.

21 de Greef BTA, Hoeijmakers JGJ, Gorissen-Brouwers CML, et al. Associated conditions in small fiber neuropathy - a large cohort study and review of the literature. Eur J Neurol 2018;25:348-55.

22 Wallis YP, McAnulty, C S. Practice guidelines for the evaluation of pathogenicity and the reporting of sequence variants in clinical molecular genetics. 2013. Available: http://www.acgs.uk.com/media/774853/evaluation_and_reporting_of_sequence_ variants_bpgs_june_2013_-_finalpdf.pdf

23 Waxman SG, Merkies ISJ, Gerrits MM, et al. Sodium channel genes in pain-related disorders: phenotype-genotype associations and recommendations for clinical use. Lancet Neurol 2014;13:1152-60.

24 Han C, Hoeijmakers JG, Liu S, et al. Functional profiles of SCN9A variants in dorsal root ganglion neurons and superior cervical ganglion neurons correlate with autonomic symptoms in small fibre neuropathy. Brain 2012;135-2613-28.

25 Estación M, Han C, Choi JS, et al. Intra- and interfamily phenotypic diversity in pain syndromes associated with a gain-of-function variant of NaV1.7. Mol Pain 2011;7:92.

26 Ahn HS, Vasylyev DV, Estacion M, et al. Differential effect of D623N variant and wild-type $\mathrm{Na}(\mathrm{v}) 1.7$ sodium channels on resting potential and interspike membrane potential of dorsal root ganglion neurons. Brain Res 2013;1529:165-77. 
27 Han C, Hoeijmakers JG, Ahn HS, et al. Nav1.7-related small fiber neuropathy: impaired slow-inactivation and DRG neuron hyperexcitability. Neurology 2012;78:1635-43.

28 Hoeijmakers JG, Han C, Merkies IS, et al. Small nerve fibres, small hands and small feet: a new syndrome of pain, dysautonomia and acromesomelia in a kindred with a novel NaV1.7 mutation. Brain 2012;135(Pt 2):345-58.

29 Cregg R, Laguda B, Werdehausen R, et al. Novel mutations mapping to the fourth sodium channel domain of Nav1.7 result in variable clinical manifestations of primary erythromelalgia. Neuromolecular Med 2013;15:265-78.

30 Goldberg YP, Price N, Namdari R, et al. Treatment of $\mathrm{Na}(\mathrm{v}) 1.7$-mediated pain in inherited erythromelalgia using a novel sodium channel blocker. Pain 2012;153:80-5.

31 Meglič A, Perkovič-Benedik M, Trebušak Podkrajšek K, et al. Painful micturition in a small child: an unusual clinical picture of paroxysmal extreme pain disorder. Pediatr Nephrol 2014;29:1643-6.

32 Devigili G, Eleopra R, Pierro T, et al. Paroxysmal itch caused by gain-of-function Nav1.7 mutation. Pain 2014;155:1702-7.

33 Blesneac I, Themistocleous AC, Fratter C, et al. Rare NaV1.7 variants associated with painful diabetic peripheral neuropathy. Pain 2018;159:469-80.

34 Mulley JC, Hodgson B, McMahon JM, et al. Role of the sodium channel SCN9A in genetic epilepsy with febrile seizures plus and Dravet syndrome. Epilepsia 2013;54:e122-e126.

35 Han C, Vasylyev D, Macala LJ, et al. The G1662S NaV1.8 mutation in small fibre neuropathy: impaired inactivation underlying DRG neuron hyperexcitability. J Neurol Neurosurg Psychiatry 2014;85:499-505.

36 Huang J, Yang Y, Zhao P, et al. Small-fiber neuropathy Nav1.8 mutation shifts activation to hyperpolarized potentials and increases excitability of dorsal root ganglion neurons. J Neurosci 2013;33:14087-97.

37 Hu D, Barajas-Martínez H, Pfeiffer R, et al. Mutations in SCN10A are responsible for a large fraction of cases of Brugada syndrome. J Am Coll Cardiol 2014;64:66-79.

38 Jabbari J, Olesen MS, Yuan L, et al. Common and rare variants in SCN10A modulate the risk of atrial fibrillation. Circ Cardiovasc Genet 2015;8:64-73.
39 Neubauer J, Lecca MR, Russo G, et al. Post-mortem whole-exome analysis in a large sudden infant death syndrome cohort with a focus on cardiovascular and metabolic genetic diseases. Eur J Hum Genet 2017;25:404-9.

40 Kambouris M, Thevenon J, Soldatos A, et al. Biallelic SCN10A mutations in neuromuscular disease and epileptic encephalopathy. Ann Clin Trans/ Neurol 2017;4:26-35

41 Han C, Yang Y, de Greef BT, et al. The Domain II S4-S5 Linker in Nav1.9: a missense mutation enhances activation, impairs fast inactivation, and produces human painful neuropathy. Neuromolecular Med 2015;17:158-69.

42 Wadhawan S, Pant $\mathrm{S}$, Golhar $\mathrm{R}$, et al. $\mathrm{Na}_{\mathrm{v}}$ channel variants in patients with painfu and nonpainful peripheral neuropathy. Neurol Genet 2017;3:e207.

43 Singh NA, Pappas C, Dahle EJ, et al. A role of SCN9A in human epilepsies, as a cause of febrile seizures and as a potential modifier of Dravet syndrome. PLoS Genet 2009;5:e1000649.

44 Tang Z, Chen Z, Tang B, et al. Primary erythromelalgia: a review. Orphanet J Rare Dis 2015; 10:127.

45 Persson AK, Liu S, Faber CG, et al. Neuropathy-associated Nav1.7 variant I228M impairs integrity of dorsal root ganglion neuron axons. Ann Neurol 2013;73:140-5.

46 Kist AM, Sagafos D, Rush AM, et al. SCN10A mutation in a patient with erythromelalgia enhances C-fiber activity dependent slowing. PLOS One 2016;11:e0161789.

47 Okuda H, Noguchi A, Kobayashi H, et al. Infantile pain episodes associated with novel nav1.9 mutations in familial episodic pain syndrome in Japanese families. PLoS One 2016;11:e0154827.

48 Zhang XY, Wen J, Yang W, et al. Gain-of-function mutations in SCN11A cause familial episodic pain. Am J Hum Genet 2013:93:957-66.

49 Kleggetveit IP, Schmidt R, Namer B, et al. Pathological nociceptors in two patients with erythromelalgia-like symptoms and rare genetic Nav 1.9 variants. Brain Behav 2016;6:e00528.

50 Han C, Yang Y, Te Morsche RH, et al. Familial gain-of-function Na 1.9 mutation in a painful channelopathy. J Neurol Neurosurg Psychiatry 2017;88:233-40. 